\title{
MEDICAL AND SOCIAL ASPECTS OF OPTIMIZING THE NUTRITIONAL STATUS OF CHILDREN DEPRIVED OF PARENTAL CARE
}

\author{
Shmulich V., Grechanina Y., Staruseva V., Shmulich O.
}

Kharkiv National Medical University

\begin{abstract}
Summary. The study deals with investigation of the content of amino acids by thin layer chromatography in blood serum of 109 children in orphanage with atopic dermatitis or dysplasia of connective tissue. It showed elevated levels of tryptophan in children with atopic dermatitis, as well as the levels of proline, glycine, lysine in children with connective tissue dysplasia, which confirmed the importance of amino acid metabolism disorders in pathogenesis of these conditions. The authors elaborated an algorithm for diet correction of metabolic and intestinal disorders developing in early childhood.
\end{abstract}

Key words: atopic dermatitis, connective tissue dysplasia, amino acid composition of the blood, dietary correction.

Introduction. Nutrition is known to be the most important environmental factor determining the health of the child and basic preventive measures of premorbid alimentary-dependent states that most frequently occur in the early age.

Especially important is the organization of rational nutrition in orphanages, where the children come from the first days of life, often with different disorders of the central nervous system, genetically determined metabolic disorders, and conditions of irrational nutrition with an ongoing food sensibilization.

The first three years of life are a special period for the development of health and depend on the rational nutrition of children, because a relatively high level of metabolism, a significant rate of growth and development, as well as physical activity determine the highest and qualitatively distinctive nutritional requirements, adequate provision of which is an important medical and social challenge.

It has been proved that characteristics of early age nutrition not only plays an important role in the formation of physical health and optimal intellectual development of the child, but may define a significantly higher risk of morbidity in

Corresponding Author:

Shmulich Vadym, MD, Assistant of Department

of Pediatrics 1 and Neonatology

of Kharkiv National Medical Univeristy, Ukraine.

E-mail:shmulich_vadym@gmail.com the adult. If we consider prevention of cardiovascular diseases (coronary heart disease, arterial hypertension) in population, ranking first among the causes of death of the adult population in Ukraine, as well as the prevalence of endocrine pathology (obesity, diabetes, metabolic syndrome), then the need for rational recommendations for optimal nutrition for this category of children is a priority and is strategically important for the healthcare system as a whole.

The problems of optimization and rationalization of nutrition of children deprived of parental care are dealt with pediatricians, geneticists, nutritionists, managers of children's custodial institutions [1-6].

2. Purposes, subjects and methods:

2.1. Purpose - is to investigate amino acid composition of blood serum in children in orphanage in order to identify pathochemical profile underlying to the disease, and identify ways to its dietary correction.

2.2. Subjects \& Methods. The study involved examination of 109 children aged from 4 months to 3 years in orphanage, 18 of whom were diagnosed with atopic dermatitis (AD) in various stages, and 26 children with connective tissue dysplasia (STD), mainly dysplastic cardiomyopathy. The vast majority of children had retardation of psychomotor and speech development.

In addition to a comprehensive clinical examination of children amino acid composition 
of the blood of the observed children was analyzed by thin layer chromatography (TLC) in collaboration with Kharkiv interregional center for clinical genetics and prenatal diagnosis.

Conflict of interests. There is no conflict of interests.

3. Results and discussion. The study results indicated increased levels of both nonessential and essential amino acids in children with atopic dermatitis and connective tissue dysplasia (Figure).

However, children with AD were more regularly and continuously found an increase in the content of tryptophan, which indicated a violation of its metabolism and effects on the body of excess concentration.

In addition, children suffering from STD were shown to have increased levels of proline, glycine and lysine. Thus, the presented data demonstrate the importance of tryptophan metabolism disorders in children`s pseudoallergic skin diseases and proline, glycine and lysine metabolism disorders lead to connective tissue dysplasia due to collagen complex dysfunction.

Therefore, persistent and recurrent changes in the skin in history accompanied by delayed psychomotor development, despite of ongoing dietary correction and drug therapy can be explained by the impairment of amino acid metabolism, in particular tryptophan. It was confirmed by a successful use in children with severe tryptophan acidemia diet with restriction of protein content in the diet, and exception of tryptophan-containing products.

The positive effect consisted in reduction of exudative rash, dry skin, itching, and repeated measurements showed a decrease in tryptophan level. Dietary correction of nutrition depending on the etiologic factor causing the disease was suggested due to etiological ambiguity in the identity of clinical symptoms of pathochemical and allergic skin lesions.

The study established the difference between etiological factors in atopic dermatitis in the identity of clinical manifestations of the disease and in this regard we individualized the most unified nutrition model of children in custodial institutions, without exceeding the fixed financial budget. Solving the problem of optimization of the nutritional status of children in orphanage more globally, we proposed an algorithm for the diet of these children depending on age and probability of possible enzymopathy, food sensitization, malabsorption syndrome, dysbiosis, etc., guided by the principles of evidence based medicine.
Thus, the children of the first month of life were administered prebiotic and probiotic mixtures e.g. Nutrilon 1.

These mixtures have value for the prevention of food allergy in newborns. The addition of probiotics provides metabolic optimization of bifidobacteria and lactobacilli bacteria in the intestinal flora, improves digestion, accelerates the formation of intestinal microbiocenosis. The mixtures were used for feeding healthy infants since birth.

Considering the most probable enzymopathy of the first months of life, lactase deficiency, children with severe intestinal dysfunction should be administered NAN-lactose-free. This adapted lactose-free formula is enriched with nucleotides, which enhance the reparative processes in the intestine by selenium, contains all the necessary substances and trace elements in the amount necessary for proper growth and development of the child. Furthermore, the reduced content of phosphorous improves calcium absorption. Given the possibility of "maturation" of enzyme systems, dairy products were gradually added to the diet in which milk sugar undergoes partial fermentation splitting: acidophilic "Malyutka", acidophilic "Malysh", acidophilic "Vitalakt", as well as kefir and other acidophilus mixtures. It is possible to add all sugars except lactose. Meat, fish, eggs, vegetables and fruit should be timely added.

There are certain periods of the child life, when the first clinical symptoms of the disease are detected more frequently.

Food containing sucrose added into the child's diet triggers intestinal dysfunction (diarrhea syndrome characterized by persistent fermentation dyspepsia, flatulence, signs of dystrophy), which is not due to other reasons, the high probability of hereditary intolerance to glucose, fructose and other carbohydrates, which requires the use of elimination diet, i.e. complete exclusion of foods containing fructose, sucrose and other mono- and disaccharides [7].

There is a period when the food diet of the child includes gliadin-containing products (semolina, bread, milk formulas, which include wheat, oats, rye, barley). Under these circumstances, the child may be intolerant to cereals (celiac disease).

Proteins of cereals are represented by four fractions: albumin, globulin, prolamin and glutein.

The nutritional value of cereal proteins is defined by gluten protein fraction. Prolamin fraction is an inhibitor of cavernous hydrolases and among many intermediate protein hydrolysis products slows cavernous digestion. 


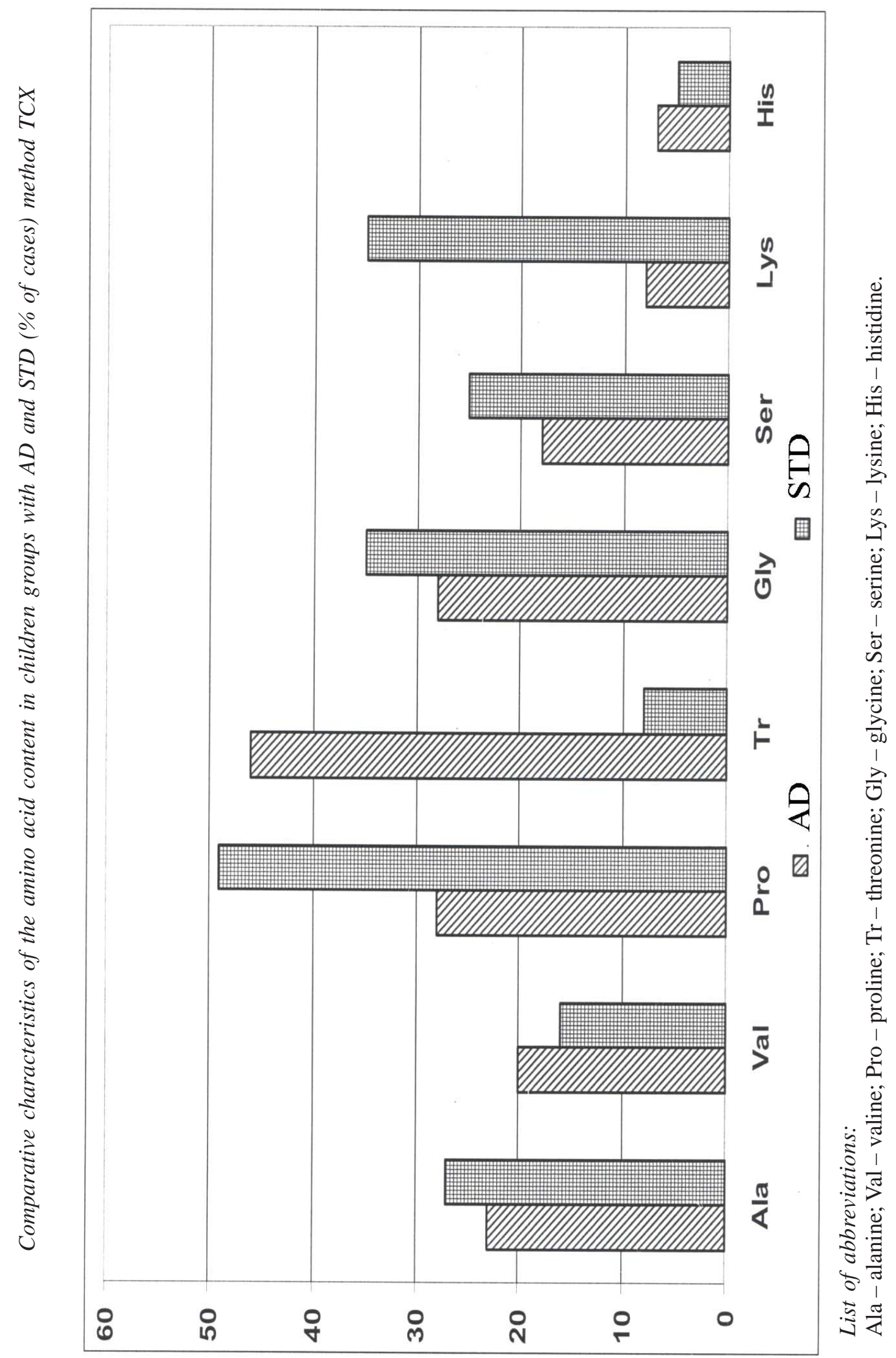


Wheat, rye and millet have the highest content of prolamins, the lowest is in buckwheat and corn.

Malabsorption and loss of protein, lipids, electrolytes, vitamins, minerals and other substances necessary for normal life of the growing organism leads to dystrophy, anemia, rachitis, polyhypovitaminosis.

Gliadin diet is the basis of treatment of celiac disease in children. The diet excludes products containing wheat, barley, oats; it is advisable to use meals with rice, corn, buckwheat, soybeans.

A special place is occupied by the diet in the conditions of maldigestion due to functional and organic changes. These are malabsorption syndrome, primary and secondary enzymopathy, mucoviscidosis, dysbacteriosis, etc. These pathological conditions require a rather strict diet, which is not always possible in numerous groups of children.

In chronic non-specific diseases of the intestine the diet should have increased protein content, physiological intake of fat and a limited intake of carbohydrates. The diet should exclude milk, gluten, disaccharides, raw vegetables and fruit, fermented-milk mixture for infants.

An increase in the protein content is achieved by meat, fish, grated cheese, protein omelets, it is necessary to enrich food with polyunsaturated fatty acids (vegetable oil, butter).

Diet therapy is the main method of treatment of atopic dermatitis in children with food allergy.

Diet therapy for patients with food intolerance is the basis, sometimes the only effective treatment. In addition to its primary purpose, providing nutrients and energy, diet therapy offers great diagnostic possibilities and has a preventive value [8].

Therapeutic and preventive mixtures with partial protein hydrolysis are used in the presence of elementary signs of atopy (diaper rash, gneiss, cradle cap). Mixtures with dietary lectins have prebiotic activity. Oligosaccharides stimulate bifidobacteria and lactobacteria in the intestine, improve digestion and do not contain gluten. Such mixtures are Nutrilon HA 1, Nutrilon HA 2, Nutrilon-comfort-1, Nutrilon-comfort-2.

In manifestations of food allergy and malabsorption syndrome the diest should include therapeutic mixtures with a high degree of protein hydrolysis (half-elemental).

Protein components consisting of short peptides and free amino acids have hypoallergenic properties and high biological value and do not contain gluten, lactose. These are "NutrilonPepti", "Nutricia" (Holland), high-grade, highly adapted mixtures for feeding children from birth to the first year of life or older.

Focusing on the terms of adding complementary food, at this age it is necessary to add partially adapted protein milk mixtures with probiotics (galactooligosaccharides), optimal content of essential microelements (iron, zinc, manganese, copper) in necessary quantities (Humana Folgemilch-2). Galactooligosaccharides are energy substrate for populating the intestine with bifidobacteria and lactobacteria with the ability to bind and remove toxic substances from food.

"Bona" is a milk mixture, which protein fractions are distributed similarly to those in breast milk; therefore proteins are more easily and quickly digested.

The complementary food in atopic dermatitis should be administered at 4.5-5 months, vegetable puree excluding brightly colored products is recommended as the first complementary food.

At 6 months the diet should comprise cereals without gluten, such as rice, buckwheat, as part of hypoallergenic mixture or vegetable broth.

It is necessary to add to the porridge $1 / 4,1 / 3$, $1 / 2$ of egg yolk as a source of vitamin D according to age. At 7 months the diet should include vegetable soup with butter or vegetable oil, kefir with cottage cheese as a source of protein and calcium. Minced meat (veal without hyperuricemia or chicken) should be added at 7.5 months, at 9 months it is recommended to add steamed cutlet.

Early artificial feeding of children with hereditary predisposition should not include corrective additives, the factors contributing to manifestation of atopic dermatitis. In this regard the delayed administration of corrective additives, using the highly adapted dairy mixtures, such as casein hydrolysates or mixtures based on soybean is a prerequisite in prevention and treatment of allergic diseases in infants.

In case of intolerance of cow's milk protein, the child's diet excludes whole cow's milk, and products prepared on its basis. Elimination diet is followed for one year, then it is possible to gradually add fermented-milk products, their volume should increase gradually.

Good effect is ensured by the use of adapted dairy-free mixtures based on soy milk "NANsoy". The mixture used for children with allergies to cow's milk protein or its intolerance, lactase deficiency, including transitory intolerance to sucrose, galactosemia. "NAN-soy" is characterized by a high degree of purification, soy protein component has a complete amino acid 
composition, is enriched with taurine, methionine and has the optimal content of L-carnitine.

Multiple causes of children`s diarrhea can include exudative enteropathy (intestinal lymph loss syndrome, protein diarrhea, intestinal lymphangiectasia). In this disease the diet should contain a high content of protein; it is advisable to limit the amount of fat to reduce stress of lymph circulation in the intestine; preference is given to fats which contain polyunsaturated fatty acids.

Hypoallergenic half-elemental mixture with low osmotic activity "Alfare" for feeding the children since neonatal period can reduce diarrhea, the severity of malabsorption syndrome and malnutrition.

The mixture is based on whey protein hydrolysate, which consists of $80 \%$ of oligopeptides and $20 \%$ of free amino acids, which prevents allergy to protein and secondary malabsorption. At the same time the child receives all the necessary micronutrients for normal growth and development. Creation of favorable conditions for active obligate growth of intestinal microflora is one of the major problems during the treatment of children suffering from intestinal dysbiosis.

It is necessary to use adapted milk products "Vitalakt", mixture "Malyutka", as well as dairy versions of adapted mixtures, such as acidophilic mixture "Malyutka", "Adapted biolact", sour milk "Vitalakt".

Administration of milk mixtures "NaN-new", "Bona", "Nestogen" has recently become common.

"NaN-new" is dairy mixture intended to feed children since neonatal period. Unique protein complex made it possible to approximate "NaNnew" to the quality of human milk. The mixture has lipid complex, enriched with fatty acids, a balanced combination of vitamins, minerals and microelements necessary for the child development. Children receiving complementary foods, should also be administered sour-milk unadapted mixtures, such as "Biolact", "Biolact2", "Narine" (Armenia), "Mazzoni" (Georgia), etc. It is useful to administer "NaN-new" with bifidobacteria, dry mixture with bifidobacteria and Streptococcus thermophilus, which provide its probiotic activity in signs of dysbacteriosis.

The use of mixtures ensures optimal intake of basic food ingredients, vitamins, microelements, minerals for proper growth and development of children since 6 months.

In addition to the progressive increase of funding the costs for children's feeding, it is important to unify and, if necessary, personalize the nutrition of this category of children.
Due to probability of lactase deficiency among children of the first month of life, it is advisable to administer "NaN-new", "NaN-lactose-free" since neonatal period.

At 2 months it is recommended to add hypoallergenic monocomponent fruit juices, puree, at 3-4 months mixture "Bona", "Nestogen", acidophilic "Malyutka", acidophilic "Malysh", acidophilic "Vitalakt".

Therapeutic and prophylactic mixtures with partial protein hydrolysis are used in case of elementary signs of atopy. These are "Nutrilon HA-1", "Nutrilon HA-2", "Nutrilon-comfort-1", "Nutrilon-comfort-2". In manifestations of atopic dermatitis it is necessary to add mixtures with a high degree of protein hydrolysis (half-elemental). These are "Nutrilon Pepto", "Nutricia" (Holland), "Bona", "Alfare", etc.

Focusing on the terms of adding complementary food (4-5 months), at this age it is appropriate to add partially adapted protein milk mixtures with prebiotics (galactooligosaccharides) and optimal content of microelements. These are "Humana Folgemilch-2", as well as non-adapted dairy mixtures "Biolact", "Biolact-2", "Narine", "Mazzoni".

Considering the possibility of manifestation of intolerance to cereals at 5-6 months it is recommended to give porridge for all children without glutein "Bananen-Milchbrei", "Fruchxe Milchbrei", "Kirsch-Bananen-Mlchbrei" and hypoallergenic dairy mixtures "Humana S7-brei", "Yreis-Milchbrei" to children with allergic history.

Mixture "O-F-plus" should be administered to preterm infants and those born with low weight.

\section{Conclusions}

1. Medical-social aspects of optimizing nutritional status of children in custodial institutions must be under the constant supervision of the social services and healthcare institutions.

2. If the diagnosis of allergic disease was verified, hypoallergenic diet for such patients should be compiled taking into account the nosological form, age and gender. For this purpose, it is advisable to use established by us as a result of population studies the degree of allergy to foods for children at different age periods, as well as the possibility of correcting the diet equivalent for the ingredient composition of the product.

3. In initial manifestations of "atopic triad" (atopic dermatitis, asthma, allergic rhinitis) dietary restrictions should comply with nosologic form described in the methodological recommendations "Determination of etiologic spectrum of allergic diseases of children by gender and age by nomographic method". 


\section{References:}

1. Grechanina E.Y., Dobrodetskaya A.L. et al. Vrozhdennye zabolevaniya metabolizma. [Hereditary disorders of metabolism]. [Article in Russian]. Ultrasound prenatal diagnostics. 2003; p:16-42.

2. Gupta R, Holdford D, Bilaver L, Dyer A, Holl JL, Meltzer D. The economic impact of childhood food allergy in the United States. JAMA Pediatr. 2013 Nov; 167(11):1026-31.

3. Clark S, Espinola J, Rudders SA, Banerji, A, Camargo CA. Frequency of US emergency department visits for food-related acute allergic reactions. J Allergy Clin Immunol. 2011; 127(3):682-683.

4. Ford LS, Taylor SL, Pacenza R, Niemann LM, Lambrecht DM, Sicherer SH. Food allergen advisory labeling and product contamination with egg, milk, and peanut. J Allergy Clin Immunol. 2010; 126(2):384-385.

5. Feklin V.A., Grechanina Y.B., Shmulich V.K., Chistilina E.Y., Pivovarova L.G. Rol' narushenij aminokislotnogo metabolizma u detej s utopicheskim dermatitom i soedinitel'notkannoj displaziej u detej iz detskih domov [The role of amino acid metabolism disorders in atopic dermatitis and connective tissue dysplasia in children from a child home.] [Article in Russian] Experimental i clinical medicine. 2005.; p:108-110.

6. Shmulich V.K., Samsonenko V.I., Dzikevich L.A., Dudulad N.M., Staruseva.V.V., Shmulich O.V. Osobennosti gipoallergennoj diety dlya detej iz detskih domov. [Features of hypoallergenic diet for children from children's homes]. Proceedings of scientific-practical conference devoted to the $170^{\text {th }}$ anniversary of the I.I. Mechnikov birth "Current issues of combating against infectious diseases"; 2015, p:34.

7. Belousov Y.V. Pediatric gastroenterology; 2007, 206 p.

8. Makeeva N.I., Myasoedov V.V., Shmulich V.K. Opredelenie ehtiologicheskogo spektra allergicheskih zabolevanij u detej v zavisimosti ot pola i vozrasta putem ispol'zovaniya nomograficheskogo metoda [Determination of etiologic spectrum of allergic diseases in children by gender and age using nomographic method] (guidelines); Kyiv. 2013, 43 p.

Received: 11-May. - 2018

Accepted: 24-Sep. - 2018 